引用格式: 高雅婵,梁勤欧,于红梅. 基于需求场理论的浙江城市水资源利用强度时空格局及演变 [J]. 资源科学, 2018,40(2): 335-346. [Gao Y C, Liang Q O, Yu H M. Spatio-temporal dynamics of the utilization intensity of urban water resource based on demand field theory in Zhejiang [J]. Resources Science, 2018,40(2) :335-346.] DOI :10.18402/resci.2018.02.10

\title{
基于需求场理论的浙江城市水资源利用强度 时空格局及演变
}

\author{
高雅婵,梁勤欧, 于红梅
}

(浙江师范大学地理与环境科学学院,金华 321004)

\begin{abstract}
摘 要: 基于城市水资源需求场理论,选取 2002-2013 年浙江省 32 个城市定量计算了不同类型城市“水(需 求)场”强度，绘制“水场”强度等值线图、“水场”强度演化趋势、“水场”方向分布图，并对城市“水场”强度时空演化 特征进行分析。结果表明: (1) 浙江省城市“水场”强度呈现东北强、西南弱的空间格局,城市规模等级越高,形成“水 场”强度越强, 对水资源的吸引、对周围一定区域的影响范围和强度越大; 随着时间演变, 研究区城市“水场”强度呈 现增强趋势; (2) 产业结构调整和政府引导对城市“水场”强度演化有重要影响; (3) 经济是浙江县级市尺度下城市 “水场”强度动态变化的重要驱动力, 该尺度下城市“水场”强度宏观分布受地形、水系、降水量等自然条件影响,局 部中、微观分布受政策、经济、人口等社会因素显著影响; (4) 不考虑“水场”各向异性时,综合各类型城市“水场”强度 演变能较好地指示城市及其经济、人口发展演变规律。
\end{abstract}

关键词: 城市水资源; 水(需求)场; 时空格局演变;需求场理论; 水场强度; 浙江

DOI :10.18402/resci.2018.02.10

\section{1 引言}

城市是人类大规模活动最频繁、活跃的区域, 随着城市化、区域一体化进程加快,各种人口、物 质、信息、能量流在城市的堣合作用强度增加,使地 球各圈层系统中天然水循环模式被强烈改变,这些 被影响的过程又通过复杂的反馈、调节影响气候变 化与城市发展 ${ }^{[-3]}$ 。变化环境下以城市为重点研究 区域的水循环演变规律及归因分析已成为目前水 资源研究的热点与难点之一 ${ }^{[4,5]}$ 。由于人工动力在 水循环中的影响越发显著, 1999 年王浩及其团队提 出了 “自然-社会” 二元水循环理论 ${ }^{[6]}$, 以海河流域为 重点开展了大量实证研究 ${ }^{[7-9]}$, 经过十几年的发展已 形成了完善的理论体系。

自物理学中 “场” 的概念引人社会学、经济学研

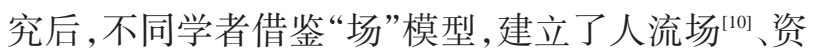

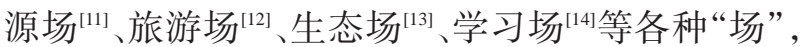
并利用其连续性、各向异性等特质对某些自然、社 会现象进行分析, 起到了不错的效果。近年来, 中 国城市化进程加快, 诸多学者将 “场”模型与经济空 间结合起来，以城市、城市腹地、城市间、城市群为 对象分别从不同的空间尺度对包括物流场 ${ }^{[15]}$ 人口 空间场 ${ }^{[16]}$ 、旱涝空间场 ${ }^{[17]}$ 、资源场 ${ }^{[18]}$ 等一系列“场”进 行了不同研究。不过,目前运用场模型对水资源需 求的研究还较少,尤其对水资源看似丰富的沿海区 域研究更少。2016 年王浩团队为解决二元水循环 理论分析过程中没有统一数理公式精确测度的问 题, 开创性地提出类比电磁场理论定量研究城市水 资源，将城市类比带负电的点 “电荷”为点 “水荷”, 其对周围空间水资源产生吸引形成类似于电场的 “水需求场”(简称“水场”), 提出“水场”强度计算公

收稿日期 : 2017-07-12; 修订日期: 2017-10-17

基金项目 : 国家自然科学基金项目(70773089)。

作者简介: 高雅婵,女,贵州毕节人,硕士生, 主要从事自然地理学及城市资源环境与可持续发展研究。E-mail: yachangao@163.com 通讯作者 : 梁勤欧,E-mail: qoliang@ @ina.com 
式, 并以海河流域为例模拟了相关城市的水资源需 求场空间分布、流动趋势 ${ }^{[19]}$ 。

在中国东部沿海经济发达地区, 以浙江为例, 虽然水资源相对内陆干旱、半干旱地区自然本底条 件较好, 但因地处亚热带季风区, 加上梅雨、伏旱、 台风等天气影响,年内降水不均,水、土资源组合与 人口、经济发展不平衡, 平原、沿海地区人口稠密、 产业集聚, 人均水资源少, 水资源有效利用率不 高。在长三角地区城市群形成、城乡一体化加速发 展的过程中,浙江“块状经济”、“产业集群”以及民 营资本活跃,受以上区位、社会、经济等多重因素叠 加影响,使该区城市水资源时空差异更加明显, 经 济发达区域水资源面临压力尤为重大 ${ }^{[20]}$ 。为保障可 持续发展,2013 年底浙江省开展了“五水共治”工 程, 从中可看出水资源问题在该区已然不容忽视, 其“自然-社会”二元水循环问题中包含的信息流已 被政府接收并产生了响应与反馈, 人地关系互动调 节的强度增加。为此,本文将基于需求场模型对浙 江省 2002-2013 年间县级市尺度城市水资源需求 的动态演变进行分析, 对城市群叠加水文效应进行 定量评估。

\section{2 研究方法与数据来源}

\section{1 方法与模型}

处于一定地理空间中的城市为维持自身生存、 发展对水资源有相应的需求,产生类似电场的“水 (需求)场”, 这种场是存在于具有吸引水资源能力 的地理实体周围, 即城市需水场力能够作用到的地 方。地理空间中包含各种地理事物与复杂的地理 过程,在 “水场”吸引水资源从周边地区流人城市的 过程中, 能对一定地理空间中的各种自然、社会过 程产生影响。若城市及其周边城市对水资源的需 求都较大, 则它们产生的“水场”相互叠加, 能对更 大空间产生影响。类比电场中的点 “电荷”, 城市对 水资源的需求形成“水荷” ${ }^{[19]}$ 。水荷”能产生 “水场”, 可以看作地理空间中事物的一种性质,地理空间中 带有 “水荷”的地理事物具有吸引周围地区水资源 的能力。类似带负电的电荷, “水荷”与地理空间 (场域)中的其它物质相互作用产生 “水场”, 使得水 资源受到需水场力吸引在空间内向一定方向流
动。“水荷量” 是对 “水荷”大小的度量, 数值上用城 市对水资源的需求量表示。电场强度是表示电场 强弱与方向的物理量, “水场”类比于电场, 故相应 的“水场”强度是衡量“水场”强弱与方向的量。在 万有引力场中, 万有引力场强度可定义为单位质量 物体受到的万有引力。基于同样的方法,单位电荷 在电场中受到的电场力为电场强度。类似地, 在 “水场”中可以定义单位体积的水资源受到的需求 引力 (需水场力) 为 “水场”强度。高斯定律认为, 电 荷产生电场, 场通过任意闭合曲面的电通量 (电场 线的数量)正比于曲面所包围的电荷总量。为便于 求取“水场”强度,陈似蓝等通过类比高斯定律提出 “水场”强度在任意闭合曲线上的线积分与闭合曲 线所包围的“水荷量”成正比,结合库仑定律得出平 面中“水场”强度的计算公式 ${ }^{[19]}$ :

$$
E=\frac{k_{W} Q}{r}
$$

式中 $E$ 为 “水场” 中某点的“水场”强度; 因“水场” 和 重力场对水的驱动在本质上有某种一致性, 可认为 单位体积水的重力场强度量纲与 “水场”强度量纲 一致, 得出 “水场”强度量纲为 $\mathrm{ML}^{-2} \mathrm{~T}^{-2} ; k_{W}$ 为 “水 场” 常数, 可以由公式 (1)推导出其量纲为 $\mathrm{ML}^{-4} \mathrm{~T}^{-2}$; $Q$ 为 “水荷量”,数值上等于 “水荷”所在城市的需水 量; $r$ 为该点到“水荷”的距离。

根据公式 (1)受单一“水荷”影响产生的“水场” 中某点 $A$ 的“水场”强度计算公式可写为 ${ }^{[19]}$ :

$$
\left|E_{A}\right|=\frac{k_{W} Q_{1}}{\sqrt{\left(x-x_{1}\right)^{2}+\left(y-y_{1}\right)^{2}}}
$$

式中 $\left|E_{A}\right|$ 为受“水荷”影响,空间中某点 $A(x, y)$ 的“水 场”强度; $Q_{1}$ 为该 “水荷” 的大小 “水荷量”; $\left(x_{1}, y_{1}\right)$ 为 “水荷”的空间坐标。

当“水场”中存在多个“水荷”时, 空间内某点 $A$ 在 $n$ 个 “水荷”叠加形成的“水场”中, 所受“水场”强 度为各个 “水荷” 产生 “水场”强度的矢量叠加, 计算 公式为 ${ }^{[19]}$ :

$$
\begin{aligned}
\left|E_{A}\right|= & k_{w} \sum_{h=1}^{n}\left[\frac{Q_{h}\left(x-x_{h}\right)}{\left(x-x_{h}\right)^{2}+\left(y-y_{h}\right)^{2}} i\right. \\
& \left.+\frac{Q_{h}\left(y-y_{h}\right)}{\left(x-x_{h}\right)^{2}+\left(y-y_{h}\right)^{2}} j\right]
\end{aligned}
$$


在不考虑 “水场” 各向异性时 $k_{W}$ 取值 $0.1^{[19]}$; 考 虑水场各向异性时, 本文对水场常数选取表征和影 响城市需水情况的城市输水网管长度、年均降水量 两项指标进行计算, “水荷” $h$ 的水场常数 $k_{W h}$ 计算公 式为:

$$
k_{W h}=0.5 G_{h}+0.5\left(1-P_{h}\right)
$$

式中 $G_{h}$ 为城市输水管网参数, $P_{h}$ 为城市降水参数。 计算公式如下:

$$
G_{h}=\frac{g_{h}-g_{\min }}{g_{\text {max }}-g_{\text {min }}}
$$

式中 $g_{h}$ 为 “水荷” $h$ 所在城市输水网管长度; $g_{\text {min }}$ 为 研究区所有 “水荷” 所在城市中输水网管长度的最 小值; $g_{\text {max }}$ 为所有 “水荷”所在城市中输水网管长度 的最大值。

$$
P_{h}=\frac{p_{h}-p_{\text {min }}}{p_{\text {max }}-p_{\text {min }}}
$$

式中 $p_{h}$ 为 “水荷” $h$ 所在城市的年均降水量; $p_{\min }$ 为 研究区所有 “水荷” 所在城市中年均降水量的最小 值; $p_{\text {max }}$ 为所有 “水荷”所在城市中年均降水量的最 大值。

\section{2 数据来源与处理}

本文研究的经济、社会数据、用水量数据主要 来自中华人民共和国住房和城乡建设部公布的《中 国城市建设统计年鉴》(2002-2013 年) ${ }^{[21]}$, 部分来 源于《中国城市统计年鉴》 ${ }^{[22]}$ 以及《浙江统计年鉴》|[23] 等。空间上选取浙江省县级市尺度,因 2013 年上虞 市调整为绍兴市上虞区, 为保证数据连贯性、稳定
性,将 2013 年前上虞市各项数据计人绍兴市计算。 自 2009年后,全省第三产业增速迅猛与之前趋势有 明显差异,故本文分 2002-2005年、2006-2009年、 2010-2013 年3个时间阶段对浙江省 11个地级市， 21 个县级市,共 32 个主要城市 “水荷”产生的城市 “水场”强度进行分析。城市作为各种物质、能量的 “汇”, 其用水基本得到了保证, 本文的需水量数值 采用城市供水量数值代替,并用“水荷量” $(Q)$ 表示, 研究区域内县级市尺度上主要城市平均“水荷”分 布及大小如图 1、图 2所示。因城市对水资源的需求 有生活、生产、市政用水等不同类型,对应产生不同

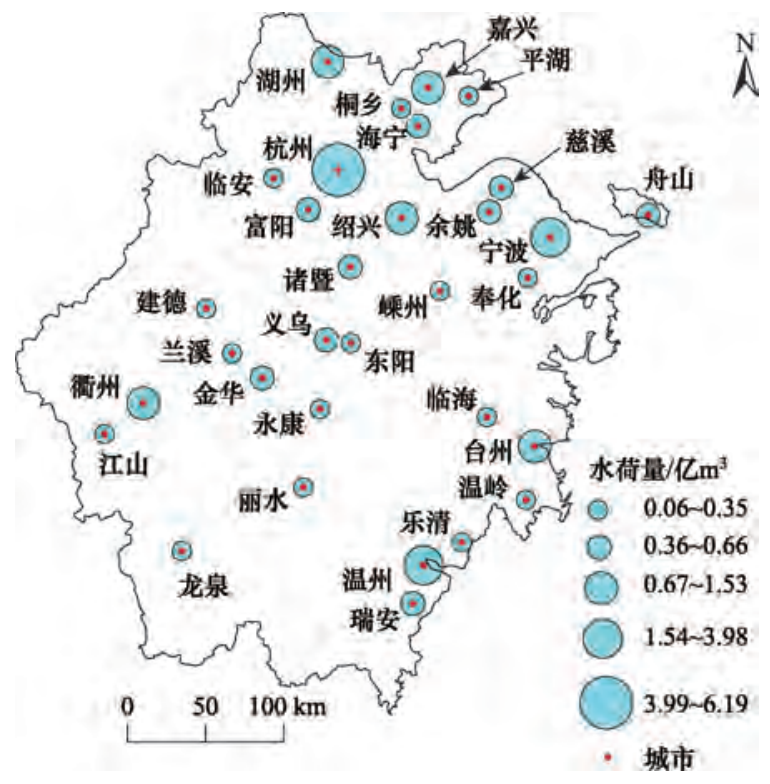

图 $12002-2013$ 年浙江省各城市“水荷”分布及水荷量

Figure 1 Distribution and quantity of urban water charges in Zhejiang Province from 2002 to 2013

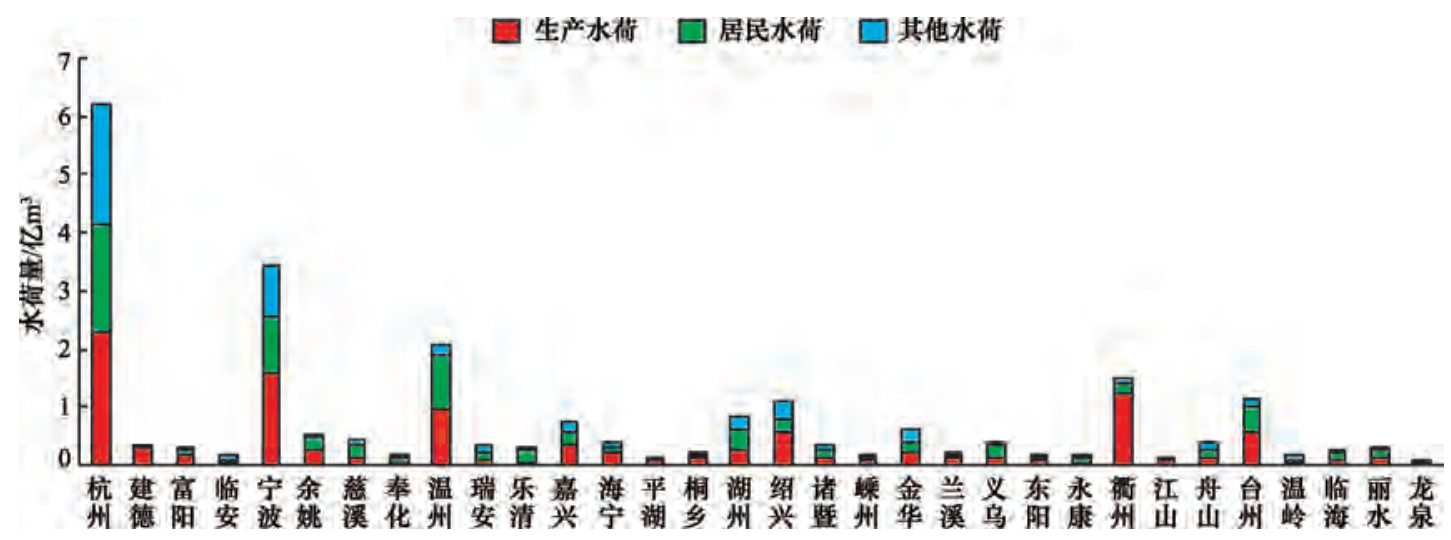

图 $22002-2013$ 年浙江省主要城市平均水荷量

Figure 2 Average quantity of water charges of major cities in Zhejiang Province from 2002 to 2013 
类型的城市 “水场”, 本文涉及了 3 种类型, 其中城市 “水场”指城市总需水场、居民 “水场”指城市居民需 水场、生产“水场”指城市生产需水场。

使用 ArcGIS 10.2 将包含研究区的最小矩形范 围进行不同分辨率的网格化 (经试验发现, 方格粒 度为 $10 \mathrm{~km} \times 10 \mathrm{~km}$ 时已能较好满足本文分析需求), 以每个方格的几何中心为待求点坐标, 代人公式 (3)分别求取不同阶段不考虑“水场”各向异性和考 虑各向异性(包括输水管网长度与年均降水量两项 指标）的城市 “水场”、城市居民“水场”、城市生产 “水场”强度,并用普通克里金法进行空间插值, 自 然断点法对各类型 “水场”第一阶段 (2002-2005 年) “水场”强度聚类,第二阶段(2006-2009年)、第 三阶段 (2010-2013 年) 分类以第一阶段分类为标 准, 绘制相应的“水场”强度等值线图、等“水场”强 度趋势图和“水场”方向分布图。

\section{3 计算结果及分析}

\section{1 城市“水场”强度时空特征分析}

\subsection{1 城市“水场”强度空间格局}

空间分布上, 离“水荷”越近, “水场”强度变化 越剧烈, 随着离 “水荷”距离增加, 城市 “水场”强度 由强到弱, 等 “水场”强度线从同心圆到不规则形态 分布 (图 3)。城市等级越高, 对应“水荷”越大, 形成 “水场”强度越强,一定范围内 “水场”强度变化幅度 越大, 对周围区域的影响范围、强度越大, 与周围其 它城市 “水荷” 产生的 “水场” 叠加耦合关系也越复
杂。图 4 中, 浙江城市 “水场”强度的高值区集中分 布于临安、诸暨、嵊州一线以东的环杭州湾地区,形 成杭州与宁波“双场核”区。其中,杭州为“主场核” 区, 其城市 “水场”与周围城市叠加耦合关系的复杂 程度、强度、影响范围为全省最大, 宁波次之。杭 州、宁波两地“水场”强度大小差距最小的阶段是 2010-2013 年,期间宁波城市“水场”强度约占杭州 的 0.68 倍。杭州城市 “水场”强度在其周围较小的 区域内先以环状分布态势急剧递减, 当“水场”强度 降低到接近临近的绍兴、海宁等次级城市“水场”强 度时,原有的同心圆等“水场”强度线结构被破坏， 在该“水场”强度上的次级城市等“水场”强度线有 被“场核区”城市吸引的趋势。各相邻次级城市间 通过水场叠加与“场核区”城市产生密切关系, 关系 复杂度与城市自身“水荷”大小、离“场核区”的空间 距离正相关。临安、诸暨、嵊州一线以西的区域,城 市“水场”强度、影响范围、相互影响程度显著小于 此线以东, 且 “水场”强度以“水荷”所在城市为中心 向周围地区迅速下降; 内陆主要呈现零星点状分布 特点, 温、台沿海平原分别以温州、台州为中心呈明 显的小团块分布。在较大的区域尺度上浙江城市 “水场”强度总体上呈现东北高、西南低的态势, 有 明显的平原、盆地指向性,沿海指向性,经济指向 性。城市“水场”在平原、多年降水量较少的区域、 经济发达地区“水场”强度较强,并形成“团块状”、 类“城市群”分布,空间分布格局与马盼盼等 ${ }^{[24}$ 基于

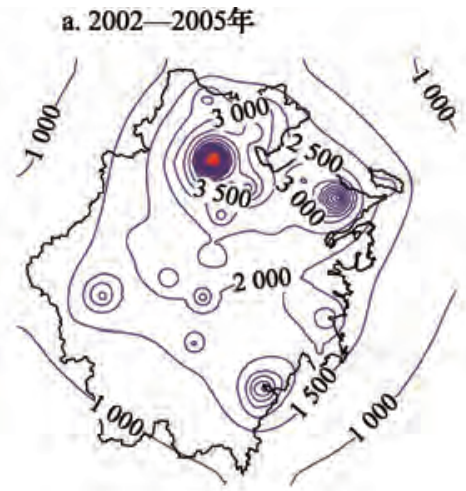

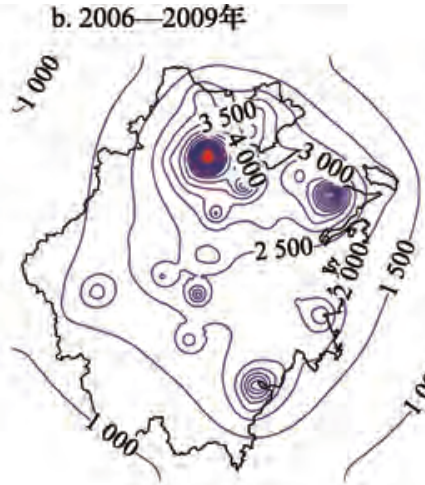

图例

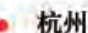

等水场强度线 $/\left(\mathrm{kg} /\left(\mathrm{m}^{2} \cdot \mathrm{s}^{2}\right)\right)$
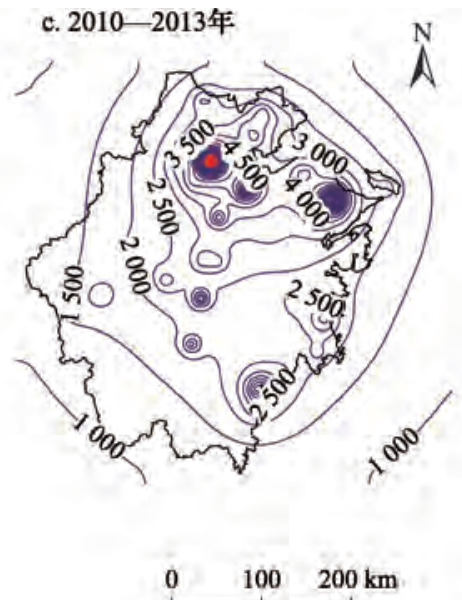

图 $32002-2013$ 年浙江城市“水场”强度等值线演化

Figure 3 Contour of urban water field intensity in the cities of Zhejiang Province from 2002 to 2013 
a. 2002-2005年总水场

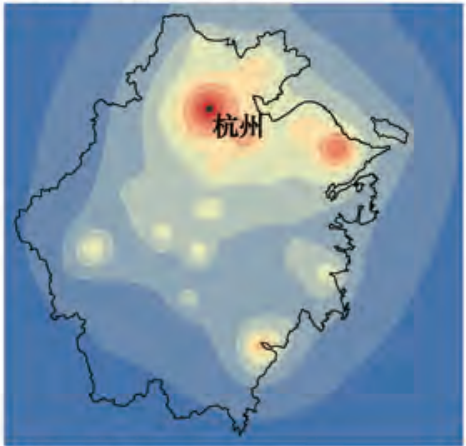

总水场强度 $/\left(\mathrm{kg} /\left(\mathrm{m}^{2} \cdot \mathrm{s}^{2}\right)\right)$

$<1110 \square 1567 \sim 2023 \square 2525 \sim 3118 \square 3847 \sim 4988 \square 6721 \sim 8911$

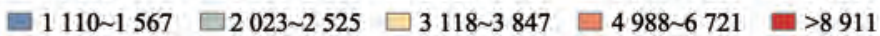

d. 2002-2005年居民水场

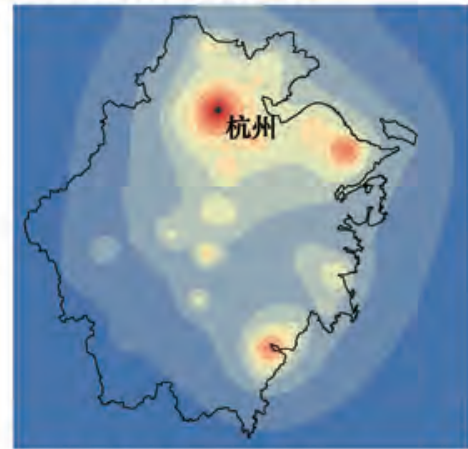

b. 2006-2009年总水场

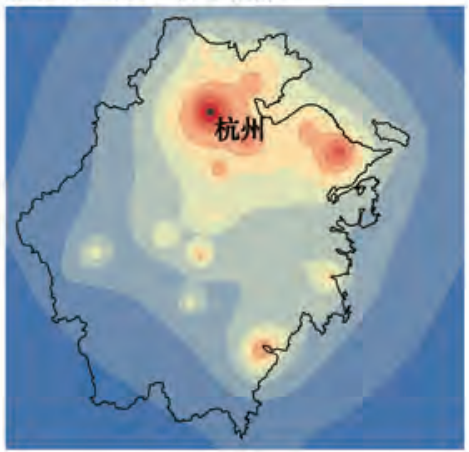

c. 2010-2013年总水场

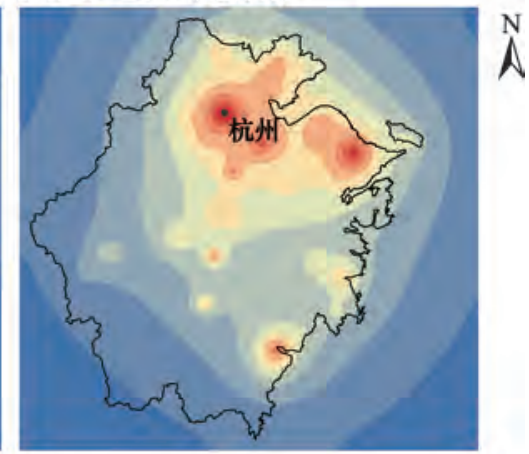

e. 2006-2009年居民水场

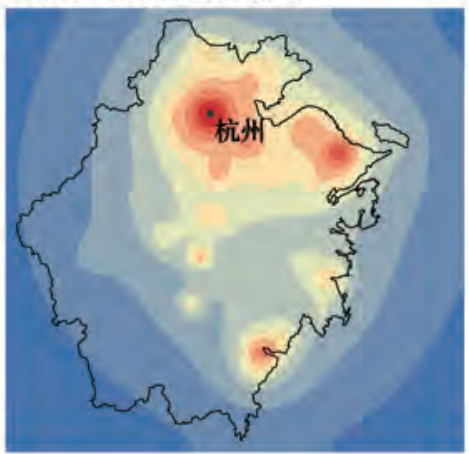

f. $2010-2013$ 年居民水场

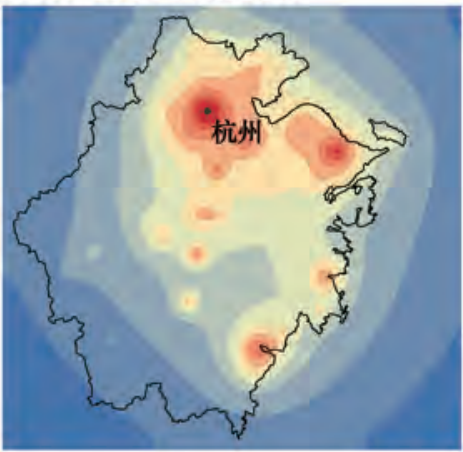

\section{居民水场强度 $/\left(\mathrm{kg} /\left(\mathrm{m}^{2} \cdot \mathrm{s}^{2}\right)\right)$}

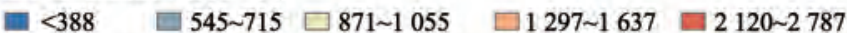
미 388 545 $\square 715 \sim 871 \square 1055 \sim 1297 \square 1637 \sim 2120 \square>2787$

g. 2002-2005年生产水场

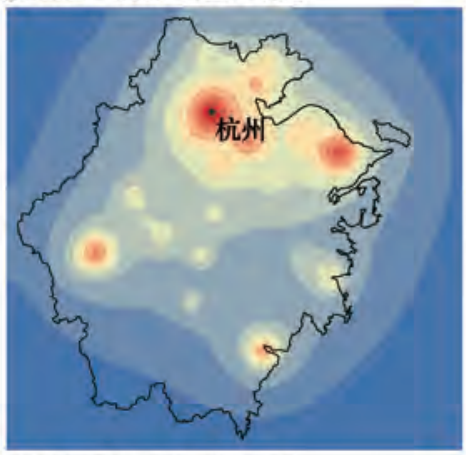

h. 2006-2009年生产水场

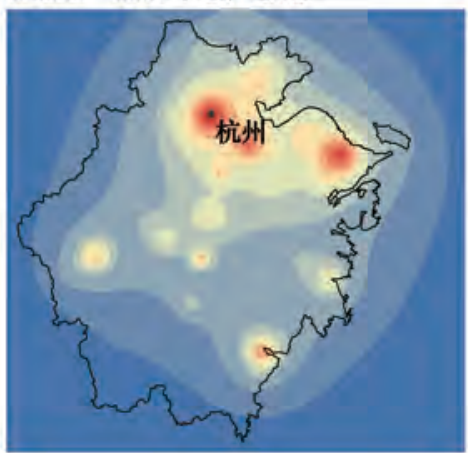

i. 2010-2013年生产水场

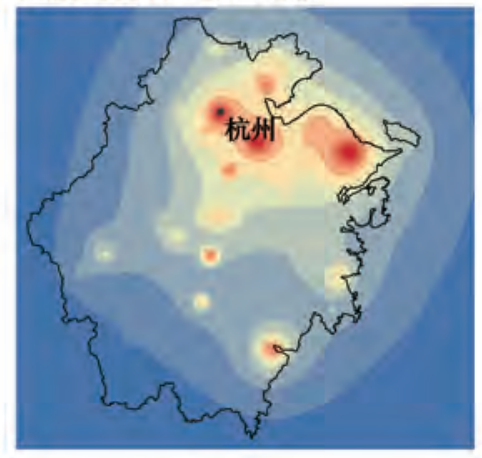

生产水场强度 $/\left(\mathrm{kg} /\left(\mathrm{m}^{2} \cdot \mathrm{s}^{2}\right)\right)$

- $<496 \square 670 \sim 879 \square 1071 \sim 1315 \square 1594 \sim 1978 \square 2501 \sim 3286$

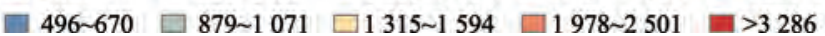

图 $42002-2013$ 年浙江主要城市不同类型等“水场”强度趋势演化

Figure 4 Trend surfaces of different urban water field intensity in Zhejiang from 2002 to 2013

遥感信息对浙江省人为热分布格局研究相似。

\subsection{2 城市“水场”强度时序演化}

从时间演化方面看,在 2002-2013 年的 3个阶 段内,全省城市“水场”强度逐渐增强,表明浙江主
要城市对水资源的需求增加。总体上,临安、诸暨、 嵊州一线以东的环杭州湾地区城市“水场”强度、影 响范围不断增加。城市 “水场”强度最大的地区始 终为杭州, 宁波次之。其中,杭州城市“水场”强度 
在第二阶段达到最高值, 此阶段比上一阶段增长了 9\%,第三阶段较第二阶段降低 $13 \%$; 而宁波城市“水 场”强度则逐阶段增加, 第二阶段和第三阶段分别 比第一阶段增长了 $14 \%$ 和 $30 \%$ 。距离杭州、宁波最 近的地区，城市 “水场”强度总体以同心圆形态逐阶 段增长, 增长形态基本保持稳定, 但一定距离之后, 随着空间上离 “场核区” 距离逐渐增加“水场”强度 减弱,在空间中的不同方向上, “水场”强度变化速 度差异较大, 环杭州湾地区形成了类似“城市群”的 城市 “水场群”分布。在高等级城市 (杭州)与其周 边次级城市 (绍兴、海宁、诸暨等)的过渡、邻接地带 “水场”叠加形成 “敏感变化区”。“敏感变化区”的 “水场”强度总体上日益增加, 影响范围也逐阶段扩 大,且 “敏感变化区”的某些演化过程使得高等级城 市, 通常也是 “场核区”城市 (杭州) 与周围其它次级 城市 (绍兴、海宁、诸暨等)关系日趋复杂、对次级城 市影响强度日益增加。处于 “敏感变化区”的城市 “水场”强度相对于场域中的其它城市变化最大, 与 城乡过渡地带的某些变化过程存在类似之处。较 低“水场”强度上次级城市等“水场”强度线有被“场 核区”城市吸引的趋势, 当吸引力增加到一定强度, 此强度等级的两个等强度区域形成一个“连接面”, 通过“连接面”相连为一个等强度区。

图 4c中, 嘉兴到丽水这一东北、西南向的“敏感 变化轴”上, 以绍兴为分界, 与前两个时间阶段相比 轴线北侧 “水场”增长强度较大、增长范围较小, 轴 线南部“水场”强度增长较小、但增长范围较大。在 第一阶段 (图 4a), 轴线南部的东阳、义乌城市“水 场”受环杭州湾城市群影响非常微弱。随着环杭州 湾地区城市 “水场”强度增加、影响范围扩大, 同时 义乌、东阳城市水资源需求量增加, 基于两者地理 位置的临近性 (相对于轴线南端的丽水), 图 $4 \mathrm{~b}$ 所示 阶段两者联系更加紧密。到第三阶段(图4c), 环杭 州湾城市群 “水场”强度在东阳、义乌方向上增长迅 速, 分别比前两阶段增长了 $14 \%$ 与 $22 \%$, 连接两者的 “敏感变化区”中 “水场”强度增长速度明显快于周 边地区, 并使得环杭州湾地区与义乌、东阳城市等 “水场”强度区连接。这一阶段, 在更弱的“水场”强 度上,金华、永康地区与浙北的相互联系、影响比上 一阶段亦有所加强, 较弱强度的等“水场”强度区已
经相连。

城市“水场”强度的时间演变与城市本身的规 模等级、临近区域内其它城市 “水荷” 的数量、大小 相关。城市规模等级高,形成高等级“场核区”的概 率亦高,处于“场核区”的城市“水场”强度空间分布 的时间演变较稳定,主要受城市自身发展影响。“场 核区”周围的次级城市 “水场”强度变化主要受自 身、“场核区”城市及两者距离叠加影响。随时间变 化“场核区”周围次级城市“水场”强度的空间变化 复杂、迅速,并且方向各异,形成“敏感变化区”。“敏 感变化区”中存在增长速度较大的优势方向, 优势 方向上往往有多个“活跃水荷”, 距离 “场核区”越近 越容易产生“活跃水荷”。“活跃水荷”所在空间的 “水场”强度增加速度和影响范围大于距离“场核 区”较远的其它普通“水荷”。

\section{2 城市居民“水场”强度与城市生产“水场”强度动 态演化}

城市居民“水场”强度总体上与城市 “水场”强 度分布、演化相类似,但影响范围、强度均小于后 者, 与周围城市关系也比后者简单。在 3 个阶段内 “场核区”城市的居民“水场”强度较稳定，“敏感变 化区”城市居民“水场”强度与影响范围增加明显。

城市生产 “水场”强度总体上仍是浙北环杭州 湾地区强于其它区域。2002-2005年这一阶段,倠 州城市生产“水场”强度在浙西南地区最强,之后的 两个阶段徵州产业结构调整,工业产值下降,唒州 城市生产 “水场”强度大幅降低, 与金华、永康之间 的区域联系也减弱。此外,浙江中部城市生产“水 场”强度有向东阳、永康、丽水一线及其以东地区增 加的趋势。整体上,2002-2013 年间浙江城市生产 “水场”强度在浙江中部及南部地区以东阳、永康、 丽水一线为界, 有自西向东转移, 内陆降低, 沿海增 加的特点。内陆地区以东阳、永康、丽水城市生产 “水场”强度增加最为明显。2006-2009年杭州生 产“水场”强度较上一阶段有所下降(图 5), 与同期 内杭州各产业类型生产总值变化情况类似。同时， 与杭州地理临近、联系密切的各次级城市生产“水 场”强度逐渐增加, 其中绍兴最为明显。2010 2013 年诸暨、海宁城市生产“水场”强度、影响范围 亦有增加, 绍兴城市生产“水场”强度已经超过杭 


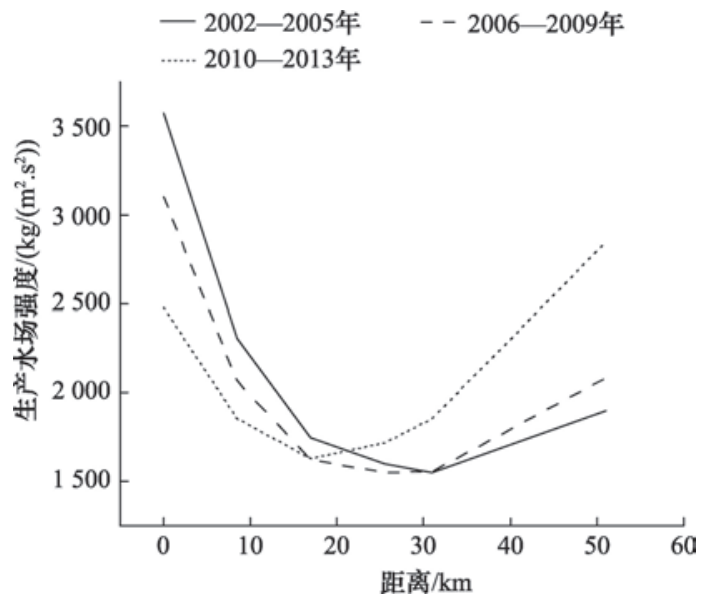

图 $52002-2013$ 年杭州到绍兴城市生产“水场”强度剖面

Figure 5 Profile of productive urban water field intensity between Hangzhou and Shaoxing from 2002 to 2013

州,受到政府相关政策调整, 对杭州城市生产“水 场”强度贡献较大的工业产业迁移、扩散到其它相 邻城市。杭州城市 “水场”强度虽然在 2010-2013 年间较2006-2009年这一阶段略有下降,但仍是全 省最强。杭州在城市居民 “水场”强度略有下降, 生 产“水场”强度显著下降的同时,其它市政及服务业 “水场”强度迅速增加, 从侧面表明其城市发展更加 多元化, 产业结构进行了调整, 城市活力进一步增 强, 区域重心地位进一步加强。与杭州不同的是, 宁波城市生产 “水场”强度稳步增加, 并且其周围次 级城市 (慈溪、余姚)生产“水场”强度也显著增加。 说明研究区域中规模、等级不同的城市, 承接的功 能具有明显的时空差异性, 在城市差异化演变中, “敏感变化区”可能对“场核区”生存发展的模式存
在某种时空上的迁移性、遗传性、继承性, 如果将这 种特性也类比为 “场”, 可以看作一种 “学习场”, 这 种“学习场”中的关键因子正是人类活动。

产业结构优化升级对“水场”强度演变起到促 进作用,政策引导对城市 “水场”有重要的反馈调节 作用。不同等级城市在一定区域中承接的区域功 能在不同时段各异,城市发展到一定规模时,需要 的资源较多,通过提高资源利用率、产业结构升级 以及政府政策引导进行优化调节, 以增加或维持其 在区域中的优势地位。同时,地理邻近的次级规模 城市, 为了自身发展可能承接原来高等级城市的一 部分产业,这个过程包含了政策引导、市场调节中 的一系列信息、资金、能量流的耦合作用。

\section{3 城市“水场”强度动态演化类型}

根据城市 “水场”强度空间分布特征与时间演 化特征, 可将浙江城市 “水场”强度空间动态演化, 归纳为以下几种主要类型 $($ 表 1$)$ 。

(1)场核型。其“水场”影响范围、强度在一定 空间范围内最大, 对水资源的需求量大,空间形态 较稳定。多分布在地势低平、人口稠密、经济发达 的沿江、沿海地带。随着选取的空间尺度、区域不 同,该类型会形成不同等级。以杭州为代表,宁波、 温州、台州也可归为此类,不过后者等级较杭州低, 相应的与周围城市关系复杂度、“水场”强度亦相对 较低, “水场”强度空间形态的稳定性相对较差。例 如,温、台沿海平原上温州、台州各自在临近的区域 内形成小团块, 温州城市 “水场”强度大于台州。随

\section{表 1 浙江城市“水场”强度主要演变类型}

Table 1 The main types of urban water field intensity evolution in Zhejiang

\begin{tabular}{|c|c|c|}
\hline 类型 & 主要代表城市 & 特点 \\
\hline 场核型 & 杭州、宁波、温州、台州 & $\begin{array}{l}\text { 多分布于地势低平、沿海、沿江地区,经济发达, 人口稠密, 对水资源需求最大, “水场”强度大、影响范围 } \\
\text { 广, 空间形态随时间变化较稳定,处于“水场团块”、“水场群”的核心 }\end{array}$ \\
\hline 敏感型 & $\begin{array}{l}\text { 绍兴、诸暨、海宁、义 } \\
\text { 乌、东阳 }\end{array}$ & $\begin{array}{l}\text { 分布在场核型周围,与“场核区”城市关系密切,受其影响显著。经济发展速度快,水资源需求量不断增 } \\
\text { 加,且需求总量较大; “水场”强度、影响范围较场核型小,在“水场团块”、“水场群”中各类型“水场”强度 } \\
\text { 分布时空变化较大,空间形态不稳定 }\end{array}$ \\
\hline 输出型 & 龙泉 & $\begin{array}{l}\text { 分布于浙西南山区,远离场核型。水资源丰富, 对水资源的需求量相对其它类型较小, 是水资源输出 } \\
\text { 地。“水场”强度虽略微增加,但增幅非常小, 与其它类型相比“水场”强度很弱, 且“水场”强度空间形态 } \\
\text { 随时间变化稳定 }\end{array}$ \\
\hline 降低型 & 忂州、江山 & $\begin{array}{l}\text { 分布于浙西丘陵、盆地, 离“水场群”较远,水资源较丰富。“水场”影响范围、强度有限, 与邻近“水荷”相 } \\
\text { 互影响不强; 随时间演变各类型“水场”强度降低,其中生产“水场”强度降低最为明显, 空间形态随时间 } \\
\text { 变化相对较稳定 }\end{array}$ \\
\hline 孤立型 & 舟山 & $\begin{array}{l}\text { 分布于岛屿, 淡水资源极为稀缺, 水资源可达性成本高, “水场”强度随时间演化增加, 居民“水场”强度 } \\
\text { 大于生产“水场”强度 }\end{array}$ \\
\hline
\end{tabular}


时间增长, 温、台城市 “水场”强度、影响范围增加, 相互关系以及与环杭州湾城市 “水场群”关系增 强。2010-2013 年温、台间城市居民“水场”等强度 区通过温岭作连接由团块分布演变为条带状分布 (图4f)。

(2)敏感型。分布在 “场核区”城市周围,与 “场 核区”城市关系复杂。城市发展速度快, 对水资源 的需求量较大。城市 “水场” 强度总体上随时间演 化增加, “水场”强度空间形态不稳定, 在 “水场团 块”、“水场群”中各类型 “水场”强度分布时空变化 较大。根据离 “场核区”城市远近、城市自身等级不 同而分为不同等级, 以绍兴、诸暨、海宁、义乌、东阳 等为典型代表。如,丽水位于 “水场”强度变化较大 的“敏感变化轴”南部端点, 在该轴线上距离杭州最 远,2002-2005 年间受环杭州湾“水场”影响极弱。 之后随环杭州湾城市群“水场”强度增加,丽水城市 需水量增加,在东阳、永康一线上丽水的城市等“水 场”强度区有与环杭州湾等“水场”强度区连接的趋 势,但较之轴线上其它距离环杭州湾“水场群”较近 的城市,其变化强度较弱。

(3)输出型。分布在浙西南山区,水资源丰富, 自身需水量小,需水量变化不大甚至下降, 是水资 源的输出地。空间上远离场核型城市, 虽然城市 “水场”强度随时间略微增加, 但增幅较小, 且 “水 场”强度空间形态变化非常小。这一类型中最典型 的是龙泉市,龙泉市水资源丰富,在研究区的 32 个 主要城市中 “水场”强度最小, 仅占杭州同时期的 7\%左右, 其周围地区并没有形成明显的同心圆影响 结构。随时间变化龙泉城市 “水场” 强度有小幅增 加, 但该市总需水量在 3 个阶段内却是逐次下降 的。其中, 龙泉市生产需水量逐阶段减少, 同时生 产“水场”强度在 3 个阶段内也依次降低。

(4)降低型。分布于丘陵、盆地地区, 水资源丰 富,远离“水场群”地区。一方面,由于该类型分布 地区为进一步发展,进行产业结构调整升级和政策 引导, 高耗水工业转移; 另一方面, 该类型分布地区 空间上距离环杭州湾和沿海地区较远, 相互叠加影 响作用弱。导致此类型城市 “水场”强度总体下降, 城市生产 “水场”强度下降明显, “水场”影响范围较 小、强度弱, 与周围城市联系亦较弱, “水场”强度空
间形态随时间变化相对较稳定。以瞿州为代表, 其 城市各类型 “水场”强度总体下降, 尤以城市生产 “水场”强度降幅最为明显, 城市居民“水场”强度在 2010-2013 年有所上升,但幅度较小, “水场”影响 范围、强度有限, 甚至与邻近的江山市也未能形成 较强的相互影响关系。

(5) 孤立型。分布于与大陆隔离的岛屿,淡水 资源稀缺, 城市 “水荷”较大, 城市居民 “水场”强度 大于城市生产“水场”强度。以舟山为代表, 淡水资 源十分稀缺, 主要满足生活供水,生产用淡水较 少。舟山城市“水场”强度逐阶段增加,但与浙江省 大部分地区不同; 此区,生产“水场”强度小,居民 “水场”强度大。由于本文并未考虑舟山属于岛屿， 淡水资源匮乏, 水资源可达性成本高, 故舟山实际 城市“水场”强度应比目前的计算值更大。

\section{4 城市“水场”作用下水资源流向趋势}

从研究区 2010-2013 年平均城市“水场”方向 分布图 6 看来 (箭头未考虑“水场”强度大小), 浙江 省水资源在“水场”的吸引下由山区流向平原,多年 降水量大地区流向多年降水量少地区,经济欠发达 地区流向发达地区。在需水场力作用下水资源在 浙江中部、南部以丽水、义乌、东阳一线为界, 以西 呈明显的西南至东北流动趋势, 以东呈自西向东流

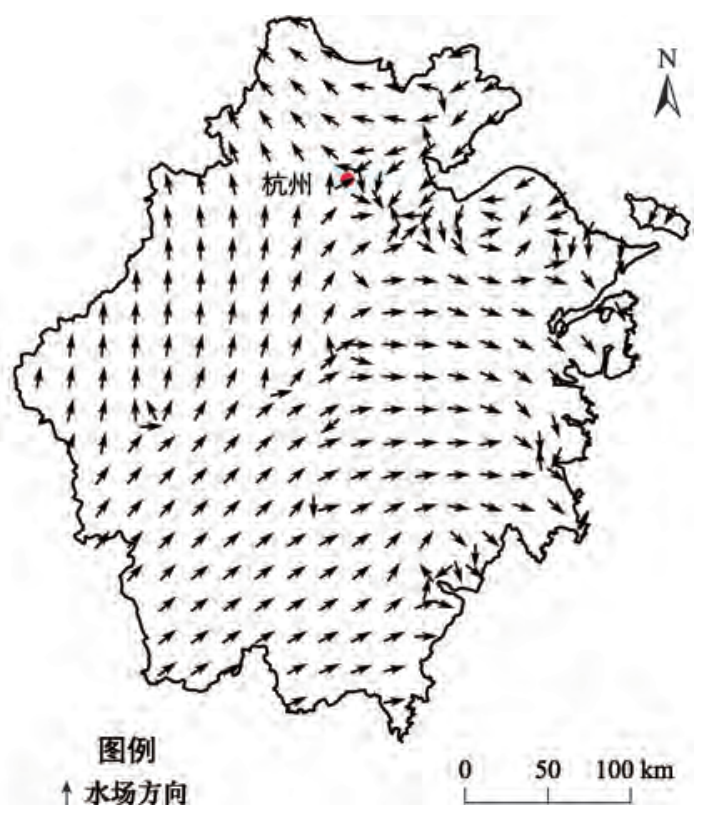

图 $62010-2013$ 年浙江平均城市“水场”方向分布 Figure 6 Distribution of the average water field direction in Zhejiang from 2010 to 2013 
动趋势, 总体上与浙江八大水系中除苕溪、曹娥江 水系的其它水系流向相对应。浙北环杭州湾地区 城市“水场”强度方向变化较为复杂。在沿海一定 范围内“水场”方向与河流流向相反并未人海,而是 受需水场力作用流向 “水场”强度高值区, 与城市对 水资源有较强吸引作用的实际相符。

本文研究尺度下城市 “水场” 宏观分布受到地 形、水系、降水量等自然条件影响,随着城市发展到 一定阶段, 成为各种物质、能量流的“汇”。这种全 局性影响在局部中、微观分布上受社会、经济、人口 因素显著影响并使自然本底“水场”改变。不过,自 然、社会、经济因素间的相互耦合作用是极其复杂 的,在规模、等级、区域作用各异的城市发展的不同 阶段,自然、社会、经济因素影响权重各不相同。

重力通过地势、地貌对水的流动起作用, 太阳 辐射通过蒸发、降水影响“水场”。自然条件下,短 时间尺度上重力 (地势、地貌) 对 “水场”影响的变率 较小,气候、降水影响的变率较大。降水量、地形等 自然因素影响了“水场”的基质条件、各地理空间自 身获得水资源的难易程度, 对城市 “水场”宏观分布 起到重要影响。同时,这种全局性影响在局部中、 微观尺度上受经济、政策、人口等社会因素显著影 响, 改变了自然本底 “水场”。城市是人类智慧生物 的聚居区, 其形成之前主要受自然驱动力影响在地 势低平的沿江、沿海地区水资源及其它各种资源形 成“汇”, 利于生物的生存、发展, 为城市及城市 “水 场”形成提供了物质基础。自然过程提供的水资源 有一定阈值, 当城市的需求接近或超过自然驱动力 提供资源的上限时, 为维持城市继续发展, 依赖于 人的智能的各种社会活动调整了有效利用率、增加 了城市 “水场”对水资源的吸引能力。一方面, 通过 节水、升级产业结构提高了水资源利用率; 另一方 面, 通过水库蓄水、工程引水等工程措施提升水资 源的可达性, 提高城市水资源通量, 增加了其它区 域流人城市的水资源。这一过程中, 经济是重要驱 动力, 政府政策则是有力的调节手段。随着城市发 展, 城市间的相互影响增加, 人类技术、人类对人地 关系认识的不断增长, 各种物质、能量、信息耦合关 系以及城市“水场”的发展演化也愈发复杂。

图 6 中, “水场”方向代表水资源在受到“水场”
产生的需水场力作用下的流向。“水场”方向在各 “水荷”周围的地理空间变化较大,水资源受到“水 场”吸引由“水场”强度弱的区域流向 “水场”强度强 的区域,但在区域中“水场”强度最强的中心处,被 吸引来的水资源往往又有向外偏转的流动趋势。 越接近一个孤立“水荷”所处的地区，“水场”强度越 大,使水资源由周边地区流向它的能力越强。当离 “水荷”距离小到一定程度后, “水荷”与场域中的其 它物质作用,可能在它周围出现类似感应起电的某 种现象,使得该地理空间上产生某种与原来“水荷” 同种性质的感应“水荷”。由于同种电荷相互排斥, 异种电荷相互吸引。类似的, 原来的“水荷”与感应 “水荷”之间出现排斥现象, 导致水资源流向逆转。 同时,一定的地理空间可以容纳、承载的物质实体 是有限的,虽然原来“水荷”所处地理空间的“水场” 强度很大, 吸引水资源的能力很强, 但当超过承载 力时,被吸引来的水资源易流向周边活力较强、发 展潜力较大的空间,于是“水场”方向从高“水场”强 度区偏转向空间上邻近的“水场”强度相对较低但 潜在发展活力较强的空间。研究区中 “水场”强度 最大、相互联系最为复杂的环杭州湾地区中杭州与 绍兴的轴线上,出现了“水场”方向由“场核区”向轴 线中点偏转的现象, 而轴线方向上正是“水场”变化 最大的敏感地区。

\section{5 考虑“水场”各向异性的计算结果}

运用公式 (4)对 “水场” 常数进行计算, 代人公 式(3)求取考虑“水场”各向异性时的“水场”强度。 由于本次研究对城市 “水场”各向异性的指标仅选 取了城市输水管网长度和年均降水量两项, 受到降 水因素影响,相较于前文不考虑 “水场” 各向异性、 “水场” 常数取定值的计算结果, 浙西南和沿海平原 地区城市“水场”强度有所下降,浙北地区“水场”强 度变化趋势不够明显, 与浙北环杭州湾地区、温台 沿海地区城市水资源紧张,输水、调水工程兴修的 事实有所差异。说明浙江省城市 “水场”强度在县 级市年际研究尺度下, 不考虑等权重输水管网长度 和年均降水量两项指标的“水场”各向异性时,浙江 城市“水场”强度时空演化作为研究浙江城市、经济 及产业类型等社会现象演化的指标效果更好。可 能的原因是在浙江城市发展的现阶段, 人类可通过 
水利工程进行引水、蓄水供给,降水因素对城市“水 场”影响有限, 而计算对降水因素引人权重过高, 对 结果造成了一定的影响, 这从侧面说明在该研究尺 度下,社会因素相较于自然因素对浙江城市“水场” 的影响权重更大。在进一步研究中,应加人更多指 标, 并找出可行方法确定各指标较为合理的权重。 此外, 降水因素对城市总需水量影响不大, 降水量 通过改变城市自身供水能力, 影响受“水场”作用从 周边地区流人城市的水资源量, 而不影响城市对周 边地区水资源的吸引能力。总需水量一定时, 城市 “水场” 具有的对周围地区水资源吸引能力一定, 在 考虑降水差异性的“水场”中某城市某年降水多时， 由于自身可提供的水资源较多,不需要从周围地区 吸引更多的水资源即可满足自身需求,故周围地区 受“水场”作用流人城市的水资源量减少。考虑各向 异性与不考虑各向异性时的“水场”结合能更客观、 准确地描述城市内部与城市外部水资源的供需来 源和数量。在不讨论自然环境需水量的前提下,不 考虑各向异性时的“水场”,表征了城市内人类社会 活动的实际需水情况, 可以作为衡量城市经济、政 策、人口发展、变化的指标之一。借助场模型便于 和其他资源、能源指标结合, 定量研究区域城市群 叠加不同资源 “需求场” 后经济、人口等社会因素与 自然因素在城市内部、城市间以及城市群的相互耦 合关系及发展演变。

\section{4 结论与讨论}

(1)浙江省县级市尺度下, 城市 “水场” 呈现东 北强、西南弱的空间分布格局, 水资源在城市 “水 场”作用下有自山区流向平原, 多年平均降水量多 区域流向降水少区域, 经济欠发达地区流向发达地 区的趋势。城市规模越大、等级越高对应 “水荷”越 大, 形成的 “水场”强度越强, 对水资源的吸引、对周 围一定区域的影响范围和强度越大, 与其它城市 “水场”的叠加耦合关系也越复杂。

(2)城市 “水场”强度的时间演变与城市自身规 模等级, 临近区域内城市数量、等级, 各自需水量大 小、类型及相距距离相关。不同 “水场”强度的地 区，“水场”随时间演化的主要形式不同：“场核区” 中城市 “水场”强度空间分布形态在时间演变中较 稳定, 主要受城市自身发展影响; 而“场核区”周围
的“敏感变化区”主要受自身和高等级城市叠加影 响, 其“水场”强度变化较大,与高等级城市距离越 近、联系越密切，随时间的空间变化越复杂、迅速， 且这种变化是方向各异的,有一个到几个优势方 向,在优势方向上增长速度较大。

(3) 浙江省城市 “水场”在县级市年际研究尺度 下，通过比较不考虑“水场”各向异性与考虑“水场” 各向异性(等权重输水管网长度、年均降水量两项 指标) 的“水场”强度,发现前者比后者能更好地反 映浙江省城市、经济、产业类型、人口分布演化, 后 者与前者结合利于讨论 “水场”作用下流人城市水 资源的供给来源与比例关系。在当前研究时空尺 度和研究区域内, 研究结果显示: 整体上,自然因子 对浙江城市 “水场”强度时空演化的影响权重小于 社会因子。现阶段,经济是浙江县级市尺度下城市 “水场”强度动态变化的重要驱动力。由于本文选 取的指标较少,且是等权重的,下一步应该增加指 标, 探究确定各指标权重的方法,或者引人水资源 可达性、可达成本等概念对 “水场常数”计算方法进 行调整。2013年底,浙江省提出并施行“五水共治” 工程,政府政策对本区城市“水场”强度分布及演变 的影响以此为时间节点差别较大, 本文暂时没有讨 论“五水共治”工程开展后的城市“水场”强度分布 及演化, 将在积累一定数据后进一步研究。

\section{参考文献(References):}

[1] Song S, Xu Y P, Zhang J X, et al. The long-term water level dynamics during urbanization in plain catchment in Yangtze River Delta[J]. Agricultural Water Management, 2016, 174: 93-102.

[2] 刘家宏, 王浩, 高学点, 等. 城市水文学研究综述[J]. 科学通报, 2014, 59(36): 3581-3590. [Liu J H, Wang H, Gao X R, et al. Review on urban hydrology[J]. Chinese Science Bulletin, 2014, 59 (36): 3581-3590. ]

[3] Champollion C, Drobinski P, Haeffelin M, et al. Water vapour variability induced by urban/rural surface heterogeneities during convective conditions[J]. Quarterly Journal of the Royal Meteorological Society, 2009, 135(642): 1266-1276.

[4] 张建云, 宋晓猛, 王国庆, 等. 变化环境下城市水文学的发展与 挑战-I. 城市水文效应[J]. 水科学进展, 2014, 25(4): 594-605 [Zhang J Y, Song X M, Wang G Q, et al. Development and challenges of urban hydrology in a changing environment: I. Hydrological response to urbanization[J]. Advances in Water Science, 2014, 
25(4): 594-605. ]

[5] 王浩, 严登华, 贾仰文, 等. 现代水文水资源学科体系及研究前 沿和热点问题[J]. 水科学进展, 2010, 21(4): 479-489. [Wang H, Yan D H, Jia Y W, et al. Subject system of modern hydrology and water resources and research frontiers and hot issues[J]. Advances in Water Science, 2010, 21(4): 479-489. ]

[6] 王浩, 王建华, 秦大庸, 等. 基于二元水循环模式的水资源评价 理论方法 [J]. 水利学报, 2006, 37(12): 1496-1502. [Wang H, Wang J H, Qin D Y, et al. Theory and methodology of water resources assessment based on dualistic water cycle model[J]. Journal of Hydraulic Engineering, 2006, 37(12): 1496-1502. ]

[7] 刘家宏, 秦大庸, 王浩, 等. 海河流域二元水循环模式及其演化 规律 [J]. 科学通报, 2010, 55(6): 512-521. [Liu J H, Qin D Y, Wang $\mathrm{H}$, et al. Dualistic water cycle pattern and its evolution in Haihe river basin[J]. Chinese Science Bulletin, 2010, 55(6): 512521.]

[8] 王浩, 贾仰文, 杨贵羽, 等. 海河流域二元水循环及其伴生过程 综合模拟[J]. 科学通报, 2013, 58(12): 1064-1077. [Wang H, Jia Y W, Yang G Y, et al. Integrated simulation of the dualistic water cycle and its associated processes in the Haihe river basin[J]. Chinese Science Bulletin, 2013, 58(12): 1064-1077. ]

[9] 王浩, 贾仰文. 变化中的流域 “自然-社会”二元水循环理论与研 究方法[J]. 水利学报, 2016, 47(10): 1219-1226. [Wang H, Jia Y W. Theory and study methodology of dualistic water cycle in river basins under changing conditions[J]. Journal of Hydraulic Engineering, 2016, 47(10): 1219-1226. ]

[10] 喻斌. 行人流场论[J]. 同济大学学报: 自然科学版, 2014, 42(2): 246-251. [Yu B. Field theory of pedestrian flow[J]. Journal of Tongji University (Natural Science), 2014, 42(2): 246-251.

[11] 董瑜, 谢高地. 资源场理论及其在资源流动中的应用 [J]. 地理科 学, 2001, 21(5): 407-411. [Dong Y, Xie G D. Pilot study of resources field theory and its application to resources flow[J]. Scientia Geographica Sinica, 2001, 21(5): 407-411. ]

[12] 章锦河, 张捷, 刘泽华. 基于旅游场理论的区域旅游空间竞争研 究[J]. 地理科学, 2005, 25(2): 248-256. [Zhang J H, Zhang J, Liu Z H. A study on spatial competition among tourism regions based on the theory of tourism field[J]. Scientia Geographica Sinica, 2005, 25(2): 248-256. ]

[13] 王根轩. 生态场理论[J]. 地球科学进展, 1993, 8(6): 76-78. [Wang G X. Theory of ecological field[J]. Advances in Earth Science, 1993, 8(6): 76-78. ]

[14] 苗长虹, 艾少伟. “学习场”结构与空间中的创新[J]. 经济地理, 2009, 29(7): 1057-1063. [Miao C H, Ai S W. Innovation in space: a new perspective of learning field[J]. Economic Geography, 2009, 29(7): 1057-1063. ]
[15] 杨洋, 张淑蕾, 王秀芹. 基于分数维场论的物流场研究[J]. 渤海 大学学报(自然科学版), 2016, 37(3): 261-265. [Yang Y, Zhang S L, Wang X Q. Research of logistics field based on field theory in the fractal dimension[J]. Journal of Bohai University (Natural Science Edition), 2016, 37(3): 261-265. ]

[16] 代富强. CA-AR 模型在人口空间场属性变化模拟中的应用[J]. 测绘科学, 2008, 33(S1): 170-172. [Dai F Q. Application of CAAR model in simulation of attribute changes of population spaces field[J]. Science of Surveying and Mapping, 2008, 33(S1): 170-172. ]

[17] 侯威, 杨萍, 郑志海, 等. 基于联合熵的旱涝空间场关联性研究 [J]. 物理学报, 2009, 58(3): 2106-2112. [Hou W, Yang P, Zheng $\mathrm{Z} \mathrm{H}$, et al. Research on the correlation of drought flood spatial fields by using joint entropy[J]. Acta Physica Sinica, 2009, 58(3): 2106-2112.]

[18] 周洪, 谷树忠, 姚予龙, 等. 基于资源场势的我国煤炭空间配置 特征研究[J]. 自然资源学报, 2013, 28(7): 1094-1105. [Zhou H, Gu S Z, Yao Y L, et al. Characteristics of coal resources spatial allocation in China: based on resource field and potency[J]. Journal of Natural Resources, 2013, 28(7): 1094-1105. ]

[19] 陈似蓝, 刘家宏, 王浩. 城市水资源需求场理论及应用初探 $[J]$ 科学通报, 2016, 61(13): 1428-1435. [Chen S L, Liu J H, Wang H. Initial research on the theory and application of urban water demand field[J]. Chinese Science Bulletin, 2016, 61(13): 14281435. ]

[20] 叶玮. 浙江地理[M]. 北京: 北京师范大学出版社, 2013. [Ye W. Geography of Zhejiang[M]. Beijing: Beijing Normal University Publishing House, 2013. ]

[21] 中华人民共和国住房和城乡建设部. 中国城市建设统计年鉴 [M]. 北京: 中国统计出版社, 2003-2014. [Ministry of Housing and Urban-Rural Construction of the People's Republic of China. China Urban Construction Statistical Yearbook[M]. Beijing: China Statistics Press, 2003-2014. ]

[22] 国家统计局社会经济调查司. 中国城市统计年鉴[M]. 北京: 中 国统计出版社, 2003-2014. [The National Bureau of Statistics of Social and Economic Investigation Department. China City Statistical Yearbook[M]. Beijing: China Statistics Press, 2003-2014. ]

[23] 浙江省统计局. 浙江统计年鉴[M]. 北京: 中国统计出版社, 2003-2014. [Statistics Bureau of Zhejiang Province. Zhejiang Statistical Yearbook[M]. Beijing: China Statistics Press, 2003-2014. ]

[24] 马盼盼, 吾娟佳, 杨续超, 等. 基于多源遥感信息的人为热排放 量空间化-以浙江省为例[J. 中国环境科学, 2016, 36(1): 314320. [Ma P P, Wu J J, Yang X C, et al. Spatialization of anthropogenic heat using multi-sensor remote sensing data: a case study of Zhejiang Province, East China[J]. China Environmental Science, 2016, 36(1):314-320. ] 


\title{
Spatio-temporal dynamics of the utilization intensity of urban water resource based on demand field theory in Zhejiang
}

\author{
GAO Yachan, LIANG Qin'ou, YU Hongmei \\ (College of Geography and Environmental Sciences, Zhejiang Normal University, Jinhua 321004, China)
}

\begin{abstract}
With rapid development and urbanization in China, the relationship between water resource supply and demand in southeast coastal areas is not optimistic. Here, we focused on the problem of water resources in some urban areas of Zhejiang. Based on the theory of urban water demand field, the quantitative calculation of different types of water (demand) field in 32 cities in Zhejiang Province from 2002 to 2013 was conducted. Here, water demand field intensity contour maps, water demand field intensity trend surfaces and water demand field distribution maps are drawn. Then, spatiotemporal pattern dynamics of the urban water demand field was analyzed. We conclude that the spatiotemporal dynamic of the urban water demand field of Zhejiang showed a pattern of northeast strong and southwest weak. With urban hierarchical structure higher, the water demand field intensity is stronger and its influence on surrounding areas is stronger. Overall, the water demand field intensity for the study area increased within the time window of our study. Industrial structural readjustment and government guidance have an important influence on the urban water field. At the scale of county-level city, the economy is an important driving force of urban water field dynamic changes in Zhejiang. These results show that the urban water field macro-scale distribution is affected by natural conditions such as topographic features, river systems and precipitation. While mesoscales or micro-scales indicate that the urban water field had a significant influence on social factors such as policies, economics and demographics. Without considering anisotropy, the water field can be a good indicator of the evolution law of the city and its economy and population.
\end{abstract}

Key words: urban area; water resources; Water (demand) field; Spatiotemporal pattern dynamic; demand field theory; water field intensity; Zhejiang 